\title{
Polish Society of Gynecologists and Obstetricians Guidelines for the application of hysteroscopy in gynecology
}

\author{
Mariusz Zimmer ${ }^{1}$, Michał Pomorski ${ }^{1}$, Paweł Kamiński ${ }^{2}$, Jacek Doniec ${ }^{2}$, Hubert Huras ${ }^{3}$, \\ Piotr Sieroszewski ${ }^{4}$, Jerzy Sikora ${ }^{5}$, Rafal Stojko ${ }^{6}$, Artur Ludwin ${ }^{7}$, Michal Radwan ${ }^{8}$, Tomasz Fuchs ${ }^{1}$ \\ ${ }^{1}$ 2nd Department of Gynecology and Obstetrics, Wroclaw Medical University, Wroclaw, Poland \\ ${ }^{2}$ Department of Gynecology and Oncological Gynecology, Military Institute of Medicine, Warsaw, Poland \\ 3 Jagiellonian University Collegium Medicum, Department of Obstetrics and Perinatology, Cracow, Poland \\ ${ }^{4}$ Fetal Medicine and Gynecology Department Medical University of Lodz, Poland \\ ${ }^{5}$ Department of Pregnancy Pathology, Department of Woman's Health, School of Health Sciences in Katowice, \\ Medical University of Silesia, Katowice, Poland \\ ${ }^{6}$ The Chair of Woman's Health, The Medical University of Silesia in Katowice, Poland \\ ${ }^{7}$ Department of Gynecology and Oncology, Jagiellonian University, Cracow, Poland \\ ${ }^{8}$ Department of Gynecology and Reproduction, Gameta Hospital, Rzgow, Poland
}

This guideline presents current management recommendations which may be modified and altered in justifiable cases, after careful analysis of a given clinical case, which in the future might constitute grounds for modification and updating.

\section{OBJECTIVES}

The objective of this guideline is to present up-to-date knowledge about the application of hysteroscopy in gynecology, based on the experience of the authors and reliable sources from the literature.

\section{INTRODUCTION}

Hysteroscopy is a minimally invasive procedure which is performed to diagnose and treat diseases of the uterine cavity and the cervical canal. The two types of the procedure include diagnostic and operative hysteroscopy. Diagnostic hysteroscopy allows for a direct visualization of the cervical canal, uterine cavity and tubal ostia and, if necessary, a targeted biopsy. Operative hysteroscopy facilitates intrauterine and/or intracervical lesion excision using mechanical or electrosurgical resection methods as well as laser techniques. Due to technological advances and miniaturization of the hysteroscopic tools, the number of diagnostic hysteroscopies with simultaneous excision of the lesions (the so-called 'see-and-treat' hysteroscopy) is steadily increasing $[1,2]$.
Hysteroscopy is a safe procedure and is well-tolerated by the patients [3].

\section{INDICATIONS FOR HYSTEROSCOPY}

Due to the wide range of possible applications of uterine cavity and cervical canal imaging, the list of indications for hysteroscopy continues to expand. Also, hysteroscopy allows to collect tissue samples, when necessary.

The indications for hysteroscopy include [3-7]:

- Abnormal uterine bleeding in reproductive age women;

- Post-menopausal bleeding;

- Suspicion of endometrial hyperplasia and other endometrial pathologies (endometrial polyps, diagnostic process for endometrial hyperplasia and endometrial cancer);

- Corroboration of histopathology results;

- Suspicion of submucosal or intramural fibroids;

- Suspicion of congenital uterine anomaly;

- Suspicion of intrauterine adhesions;

- Corroboration of ultrasound diagnosis of uterine abnormalities;

- Repositioning and/or removal of an intrauterine device or other foreign bodies from the uterine cavity;

- Suspicion of retained products of conception;

- Suspicion of lesions within the cervical canal;

- Part of the diagnostic process for infertility and/or recurrent miscarriage; 
- Endometrial ablation/resection;

- Vaginoscopy (e.g. removal of a foreign body from the vagina in young girls - virgo).

Indications for hysteroscopy may also include clinical situations in which uterine cavity, cervical canal and tubal ostia imaging is vital for the diagnostic and therapeutic management of the affected patients, e.g. treatment of symptomatic niche in the cesarean section scar, injection of methotrexate or other pharmacological agents into the gestational sac located in the cesarean section scar, diagnostic and/or operative hysteroscopy, with or without biopsy, before operative procedures in gynecology $[8,9]$.

In case of suspicion of intrauterine lesions, hysteroscopy is used during the diagnostic process for infertility, recurrent miscarriage or before assisted reproductive techniques (ART). At present, hysteroscopy is not routinely recommended in the diagnosis of infertility or before IVF procedures if ultrasonographic appearance of the uterus is normal [10-13].

\section{CONTRAINDICATIONS TO HYSTEROSCOPY}

Absolute contraindications to hysteroscopy include [3, 14]:

- suspected or diagnosed normal viable intrauterine pregnancy;

- active infection of the genital organs, including herpes simplex of the genital area;

- cervical cancer.

Relative contraindications to hysteroscopy include:

- excessive uterine bleeding;

- severe systemic disease.

Bleeding from the genital tract is not an absolute contraindication to hysteroscopy but obstructed visualization of the intrauterine structures may be expected. In such cases, it is necessary to select adequate instruments (flow hysteroscope with proper diameter and isoosmotic medium) [15].

\section{INSTRUMENTS}

\section{Types of hysteroscopes}

Both, for the operative and diagnostic hysteroscopy, the type of the hysteroscope should be adjusted to the type of the procedure and operator's experience, as well as modified to the intraoperative conditions $[4,16,17]$. It is advisable to use a hysteroscope with the smallest possible diameter of the sheath, individually tailored to the needs of the patient, and allowing for optimal visualization and least traumatic procedure $[3,4,18]$.

\section{Media types}

Visualization of the intrauterine structures requires distension of the uterine cavity using medium agents. The choice of the distending medium for hysteroscopy is at the discretion of the operator. At present, the $0.9 \%$ sodium chloride $(\mathrm{NaCl})$ is the liquid medium of choice for diagnostic hysteroscopy $[3,18,19]$. Other than in exceptional situations, a gaseous medium - carbon dioxide $\left(\mathrm{CO}_{2}\right)$ - is not advisable in order to avoid the presence of gas embolism [3]. Also, the use of $0.9 \% \mathrm{NaCl}$ is associated with lower frequency of vasovagal syncope as compared to $\mathrm{CO}_{2}$ [4]. A liquid medium, as opposed to gaseous one, allows to wash out the mucus and the blood from the uterine cavity, thus improving visualization and shortening the duration of the procedure $[20,21]$. For operative hysteroscopy, only liquid media are used. Their advantage consists in washing out the tissue fragments and blood which occur during intrauterine lesion excision, thus obtaining adequate view of the uterine cavity during the procedure [18-20].

Liquid media are subcategorized into:

- non-electrolyte dissension media (5\% mannitol, 3\% sorbitol, and $1.5 \%$ glycine) and

- isotonic electrolyte-containing media ( $0.9 \%$ sodium chloride, Ringer's solution).

As for electric conductivity, non-electrolyte dissension media are nonconductive, so they are used during procedures with monopolar electrodes $[3,18]$. On the downside, they are hypotonic. In the event of excessive absorption into the circulatory system, they may lead to fluid overload, hyponatremia, and lowered plasma osmolarity, which might result in cerebral edema or even death [3, 18, 22]. Electrolyte-containing media are electrically conductive and cannot be used for procedures with monopolar electrodes $[3,18-20]$. They are, however, the medium of choice for operative hysteroscopy with bipolar electrodes $[3,18]$. Their isotonicity is their primary advantage, as they reduce the risk for hyponatremia and lowered plasma osmolarity.

\section{BEST PRACTICE IN HYSTEROSCOPY} Eligibility criteria

Patients are deemed eligible for the procedure on the basis of the pelvic exam and medical history. Additionally, an ultrasonographic examination should be performed, using transvaginal probe, if possible. In justified cases, additional imaging methods (i.e. sonohysterography and nuclear magnetic resonance) may also be applied during patient eligibility check. The abovementioned methods, unlike hysteroscopy, allow for the assessment of the myometrium and the external uterine contour. Additional imaging methods, especially transabdominal or transrectal ultrasound, and sometimes laparoscopy, can be used intraoperatively and may increase both, safety and effectiveness of some advanced hysteroscopic procedures [23-25].

\section{Informed consent}

Written informed consent must always be obtained before every hysteroscopic procedure. It is necessary to 
discuss the following with the patient: hysteroscopy type, benefits and risk related to the procedure, and alternative methods of management.

\section{Timing of the procedure}

For menstruating women, the first phase of the cycle, immediately after the bleeding ceases, is the optimal time to carry out the procedure, as the endometrium in the early proliferative phase is thin and allows for a better visualization of the intrauterine structures and possible pathologies [3]. In the secretory phase, thickened endometrium may impede imaging and visualization, thus increasing the risk for misdiagnosis (underdiagnosis of small lesions and overdiagnosis of endometrial polyps).

In post-menopausal women, hysteroscopy may be performed at any given time.

\section{Cervical preparation}

Difficulty in inserting the hysteroscope through the cervical canal into the uterine cavity is among the main causes for unsuccessful hysteroscopy and is responsible for approximately $50 \%$ of the related complications $[4,26]$. Therefore, in selected cases of operative hysteroscopy, pharmacological preparation of the cervix using misoprostol (vaginally, 200-400 $\mu \mathrm{g}$ ) is allowed [3, 4, 27-30]. Randomized studies found no proof of increased number of successful procedures or lowered risk for complications or pain reduction for diagnostic hysteroscopy [27-29, 31]. Thus, routine use of misoprostol for cervical preparation before diagnostic hysteroscopy is not recommended [4].

Notably, the use of misoprostol for cervical preparation is an off-label approach.

In cases of cervical stenosis, osmotic distending media, intraoperative ultrasound, vaginoscopic approach, manual dilation and hysteroscopic dissection of the stenotic cervical canal may be also applied [26, 32].

\section{Endometrial preparation}

Pre-operative administration of the endometrial thinning agents may be considered in women undergoing elective operative hysteroscopy (e.g. uterine septum resection, submucosal fibroid resection, endometrial ablation) to ensure a better view during the procedure [33]. Such management is not recommended for diagnostic hysteroscopy as it might affect the histopathology results.

\section{Vaginal preparation}

After excluding the contraindications to hysteroscopy (like active inflammation of the genital organs), vaginal discharge ought to be examined before the procedure. If no signs of inflammation are present, hysteroscopy may be conducted. Culture of the cervix is not routinely required.
It is advisable to visualize the vaginal portion of the cervix using the speculum and wash the vagina and the vaginal portion with an antiseptic solution suitable for mucous membranes. Vaginoscopic approach (i.e. the so-called 'no touch' technique) is also allowed [4, 34, 35]. It consists in insertion of the hysteroscope into the vagina, through the cervical canal and into the uterine cavity without the use of a speculum or cervical instrumentation. Vaginoscopic approach is recommended in situations when it is difficult or impossible to insert a speculum. The procedure may be conducted without the need to disinfect the vagina if vaginal discharge is normal.

\section{Settings}

Advances in technology and increasing miniaturization of the hysteroscopes allow to conduct diagnostic and simple operative hysteroscopies in outpatient settings [4, 36, 37]. The decision between outpatient and hospital setting should be made with caution.

Hospital settings should be recommended to patients with: $[3,38]$ :

- intrauterine lesions which require advanced operative procedures;

- cervical stenosis or atresia;

- concomitant diseases which elevate the risk for complications;

- limited uterine maneuverability;

- no tolerance of local anesthesia.

In the remaining cases, ambulatory settings may be recommended to patients.

\section{Elimination of perioperative pain}

Hysteroscopy-related pain remains to be one of the main limitations for a successful procedure in ambulatory settings, so it is vital to be familiar with techniques of pain reduction $[38,39]$. Friendly atmosphere and engaging the patient in a conversation play a significant role in reducing pain and anxiety associated with the procedure [40]. Depending on the emotional condition of the patient and her attitude, anesthesia in not necessary during a diagnostic hysteroscopy in most women $[41,42]$. The benefits of avoiding anesthesia include shortened time of the procedure and no adverse effects, especially no pain associated with paracervical block [41].

Also, small-diameter sheath hysteroscopes are key elements in pain reduction. Randomized studies revealed that the use of hysteroscopes with sheath diameter less than $4 \mathrm{~mm}$ correlates with significantly less pain as compared to the use of higher diameter hysteroscopes with simultaneous paracervical block [43].

Opioids reduce pain during and after the procedure, but caution is advised due to possible adverse effects $[4,44]$. 
Non-steroidal anti-inflammatory agents (NSAIDs) do not relieve the pain during hysteroscopy but significantly reduce it after the procedure $[4,45]$. Local anesthetics, e.g. lidocaine spray on the vaginal portion of the cervix, is not an effective means of pain relief during hysteroscopy [46]. Likewise, lidocaine and mepivacaine administration into the cervical canal proved ineffective [46].

Paracervical block using lidocaine or mepivacaine reduces pain associated with cervical dilation and endometrial biopsy, and lowers the risk for severe pain during hysteroscopy [47], so it should be considered in cases when cervical dilation is necessary or when intrauterine lesions are to be removed [4, 47].

Sedation, regional or general anesthesia should not be used in ambulatory settings as they require strict monitoring of the vital signs and are connected with possible complications [48]. They should only be administered in setting where adequate anesthesiologic standards are maintained.

\section{HYSTEROSCOPIC BIOPSY}

Hysteroscopic endometrial biopsy should replace diagnostic curettage of the uterine cavity [49]. Sensitivity of the hysteroscopic endometrial biopsy is significantly higher, especially in case of focal lesions. Diagnostic curettage of the uterine cavity, if conducted as a sole diagnostic procedure, is not sufficient for full diagnostics of the endometrium in case of focal lesions [50,51]. Therefore, hysteroscopy and targeted biopsy should be considered in women with indications for histopathological examination of the endometrium (e.g. in the diagnosis of endometrial cancer) [51,52]. It makes it possible to collect focal lesions, which might otherwise be omitted during blind biopsy or curettage, for evaluation [51, 52]. In case of extensive suspicious changes in the uterine cavity, subsequent curettage is allowed.

It is not always possible to obtain enough endometrial tissue for histopathologic evaluation, especially in postmenopausal women with endometrial atrophy [53-55]. In a meta-analysis of studies on endometrial biopsy, non-diagnostic histopathology results were found in as many as $54 \%$ of the women with post-menopausal bleeding [54]. According to reliable reports in the literature, results of imaging studies are sufficient to planfurther management in case of patients with non-diagnostic histopathology results [53-55]. If hysteroscopy confirmed atrophic endometrium and histopathology results are non-diagnostic, repeat biopsy is not necessary, unless new indications are present [53-55].

\section{Risk for tumor cell dissemination in the peritoneal cavity}

Hysteroscopy is associated with a certain risk for tumor cell dissemination into the peritoneal cavity due to the passage of the medium through the fallopian tubes. The available data are not conclusive with regard to a possi- ble increase in the incidence of positive peritoneal cytology after the use of hysteroscopy in the diagnosis of endometrial cancer. So far, various meta-analyses have found a link between the use of liquid media and higher incidence of positive peritoneal cytology, but no relationship between potential tumor cell dissemination and disease progression was detected [56-61].

In order to reduce the risk for cell dissemination in cases of suspected endometrial cancer, it is advisable to use the lowest possible pressure of the distending medium, preferably not exceeding $50 \mathrm{mmHg}$. In a study using saline solution and intrauterine pressure of $25-50 \mathrm{mmHg}$, the authors found that hysteroscopy did not increase the risk for microscopic intraperitoneal tumor cell dissemination as compared to curettage [62]. More prospective studies in that area are necessary.

\section{COMPLICATIONS OF HYSTEROSCOPY AND THEIR PREVENTION}

Early complications:

- uterine perforation;

- heavy bleeding;

- absorption of the distending medium;

- gas embolism;

- fluid overload.

Late complications:

- iatrogenic adhesions after hysteroscopy;

- pelvic inflammatory disease.

\section{Uterine perforation}

The incidence of uterine perforation during diagnostic and operative hysteroscopy has been estimated at $0.13 \%$ and $0.5-3 \%$, respectively $[62,63]$. Perforation may occur either during the attempt to enter the uterine cavity or intraoperatively, during lesion excision. Risk factors for perforation during hysteroscope insertion include $[4,63]$ :

- cervical stenosis and the need for cervical dilation (as a result of atrophy, previous surgery, or no previous vaginal delivery);

- torsion of the cervical canal and uterine cavity (frequently occurs in case of fibroids and pelvic adhesions).

The highest risk for uterine perforation is associated with the excision of massive intrauterine adhesions [63]. Should perforation occur, it is possible to either monitor the patient or consider performing laparoscopy or laparotomy to stop the bleeding and assess for possible intestine or bladder trauma [3]. Assessment of the bowel and the bladder is necessary in the event of uterine perforation using an electrosurgical tool or laser due to the risk for thermal injury [64]. Suturing of the uterine perforation is advised in reproductive age women to prevent a possible uterine scar rupture during subsequent pregnancy [65]. It is important 
to bear in mind that if the perforation is localized within the cervix or the lateral uterine wall, it may cause bleeding into the retroperitoneal space [3].

If fundal perforation occurs while using a thin hysteroscope, a thin Hegar device, or an uterine probe in a post-menopausal woman without signs of bleeding into the abdominal cavity, it is possible to simply monitor the patient. Detailed imaging to exclude bleeding into the abdominal cavity and a 24-hour monitoring at a postoperative care unit are necessary. Should patient clinical and laboratory (complete blood count, C-reactive protein) parameters remain stable after 24 hours, the perforation may be diagnosed as non-symptomatic and not requiring surgical intervention.

In cases when hysteroscopic entry is difficult, it is advisable to establish the path of the cervical canal and its relation to the uterine axis before'blind' cervical dilation [3, 26]. For that purpose, a small-diameter flexible or rigid hysteroscope may be used, which allows for visual control during dilation of the cervical canal with the tip of the hysteroscope or microtools inserted through the operative channel [26]. Uterine probe, bimanual examination, transvaginal, transrectal or transabdominal ultrasound are also useful while attempting to establish the path of the cervical canal and its relation to the uterine cavity. Difficulty with hysteroscopic entry into the uterine cavity may be reduced by cervical preparation with misoprostol [29].

\section{Hemorrhage}

Clinically significant bleeding during diagnostic hysteroscopy is rare and is usually associated with uterine perforation. The incidence of clinically significant bleeding related to operative hysteroscopy has been estimated at $0.61 \%$ [63]. Apart from uterine perforation, other causes for bleeding include cervical trauma, bleeding at the operation site or bleeding diathesis.

In the event of intraoperative bleeding, coagulation using mono- and bipolar electrodes may be applied (the choice of the electrodes depends on the medium used during the procedure).

Postoperative bleeding from the uterine cavity may be stopped by using uterotonics, antifibrinolytics, or balloon tamponade (e.g. using a Foley's catheter).

If none of the above methods proved sufficient, it may be necessary to perform uterine artery embolization or hysterectomy. The patient should be made aware of that risk and information about a possible hysterectomy should be included in the informed consent for all hysteroscopic procedures $[3,63]$.

\section{Embolism}

Air embolism may occur during hysteroscopy using either gaseous medium $-\mathrm{CO}_{2}$ or liquid medium, as air bubbles are present in the liquid medium as well $[18,66]$. The symptoms include dyspnea, chest pain, tachycardia, anxiety, sudden hypotension and hypoxemia [18]. Vascular access and a pressure gradient are necessary for $\mathrm{CO}_{2}$ or air to get into the cardiovascular system, and then to the right ventricle and to the pulmonary arteries [3]. Therefore, to avoid this complication, it is vital to keep the rate of the $\mathrm{CO}_{2}$ flow below $100 \mathrm{~mL} / \mathrm{min}$., and the uterine cavity pressure below $100 \mathrm{mmHg}$ [3]. Importantly, laparoscopic insufflators should not be used for hysteroscopic procedures as they have very high $\mathrm{CO}_{2}$ flow rate [3]. Carbon dioxide should not be used during operative hysteroscopy due to the risk for $\mathrm{CO}_{2}$ passage into the open vessels [18]. To avoid air passage into the uterine cavity during hysteroscopy with liquid medium, tubing and hysteroscopy channel ought to be flushed until all air bubbles are removed. Caution is also advised when bags containing liquid media are changed to avoid air entering tubing [3].

\section{FLUID OVERLOAD}

Operative hysteroscopy intravascular absorption syndrome (OHIA) occurs when a significant amount of the liquid medium is absorbed into the circulation $[63,67]$. At present, the incidence of OHIA has been estimated at $<1 \%[18,63$, $68,69]$. The absorption occurs by the opened uterine veins as a result of pressure gradient (venous pressure: $10-15 \mathrm{mmHg}$, distending media pressure in the intrauterine cavity: 40$60 \mathrm{mmHg}$ ) [63]. Absorption of the distention media may also occur by peritoneal surface due to the retrograde passage of the fluid through the Fallopian tubes [18].

Risk factors for fluid overload include high (excessing the mean blood pressure) pressure in the uterine cavity, prolonged duration of the procedure, and contact between the medium and the opened myometrial venous sinuses (mainly during electrosurgical fibroid resection or the resection of the endometrium) [70-72].

Massive absorption of a hypotonic medium (glycine, mannitol, sorbitol) leads to hyponatremia, which is manifested with headache, nausea, vomiting and fatigue. In case when sodium levels drop below $<120 \mathrm{mmol} / \mathrm{L}$, lowered plasma osmolarity will lead to cerebral edema, including the risk for brain herniation [3, 28, 73].

Massive absorption of an isotonic medium ( $0.9 \%$ sodium chloride, Ringer's solution) will not cause electrolyte imbalance but may lead to hypervolemia with pulmonary edema and heart failure $[3,18]$.

In accordance with the international consensus, a fluid deficit (difference between the volume of fluid infused into the uterus and the volume of fluid evacuated from the uterus) should not exceed $1000 \mathrm{~mL}$ for hypotonic (glycine, mannitol, sorbitol) and $2500 \mathrm{~mL}$ for isotonic solutions. These thresholds apply to healthy reproductive age women [18]. 
In case of elderly women with renal and cardiovascular problems, the upper fluid deficit levels should be $750 \mathrm{~mL}$ and $1500 \mathrm{~mL}$, respectively [19]. Therefore, careful monitoring of the fluid deficit during hysteroscopy is necessary. The procedure should be stopped when the fluid deficit is reaching the abovementioned limits or when the clinical symptoms of fluid overload occur. In order to lower the risk for hyponatremia and the related complications, iso-osmotic media such as $0.9 \%$ sodium chloride or Ringer's solution should be the preferred choice for operative hysteroscopy [18]. The information about fluid deficit should be included in the operation report.

\section{latrogenic adhesions after hysteroscopy}

Hysteroscopic resection of the intrauterine lesions is associated with significantly lower risk for de novo adhesion formation as compared to curettage [74]. Therefore, uterine curettage in order to obtain endometrial samples in women undergoing diagnosis for infertility should be avoided. The incidence of adhesion formation after operative hysteroscopy depends on the type of the procedure. Polypectomy is associated with the lowest and multiple submucosal fibroid resection with the highest risk for adhesion formation, respectively [74]. The following procedures may decrease the risk for intrauterine adhesion formation after hysteroscopy: avoidance of electrosurgical tools, early second-look hysteroscopy, estrogen therapy, intrauterine systems (IUD, balloon), stem cells, hyaluronic acid gels or carboxymethyl cellulose gels [74-76]. At present, we lack reliable data advocating routine use of any of the abovementioned methods of preventing adhesions after hysteroscopy [75].

\section{Pelvic inflammatory disease}

The incidence of inflammatory diseases after hysteroscopic procedures has been estimated at $<1 \%$, so routine antibiotic prophylaxis is not required [77-79]. Guidelines on patient eligibility and preparation for the procedure, which constitute preventive measures for post-hysteroscopic inflammation, have been presented earlier in the text.

\section{SUMMARY}

The benefits of diagnostic hysteroscopy include direct visualization of the intrauterine structures and, when necessary, performing a minimally invasive targeted biopsy for histopathology evaluation.

Operative hysteroscopy allows for a minimally invasive excision of intrauterine lesions.

Hysteroscopy is well-tolerated and safe for the patients.

Hysteroscopy is the basis of the modern diagnostic process and the treatment of uterine diseases, and every effort should be made to increase its availability in Poland.

\section{REFERENCES}

1. Wortman M. "See-and-Treat" Hysteroscopy in the Management of Endometrial Polyps. Surg Technol Int. 2016; 28: 177-184, indexed in Pubmed: 27121409.

2. Gambadauro P, Martínez-Maestre MA, Torrejón R. When is see-and-treat hysteroscopic polypectomy successful? Eur J Obstet Gynecol Reprod Biol. 2014; 178: 70-73, doi: 10.1016/j.ejogrb.2014.03.048, indexed in Pubmed: 24792666.

3. ACOG Technology Assessment No. 13 Summary. Obstetrics \& Gynecology. 2018; 131(5): 952-953, doi: 10.1097/aog.0000000000002629.

4. RCOG/BSGE Joint Guideline. Best Practice in Outpatient Hysteroscopy. Green-top guideline. 2011(59).

5. Munro MG, Critchley HOD, Fraser IS, et al. FIGO Menstrual Disorders Committee. The two FIGO systems for normal and abnormal uterine bleeding symptoms and classification of causes of abnormal uterine bleeding in the reproductive years: 2018 revisions. Int J Gynaecol Obstet. 2018; 143(3): 393-408, doi: 10.1002/ijgo.12666, indexed in Pubmed: 30198563.

6. Hatfield JLW, Brumsted JR, Cooper BC. Conservative treatment of placenta accreta. J Minim Invasive Gynecol. 2006; 13(6): 510-513, doi: 10.1016/j.jmig.2006.06.013, indexed in Pubmed: 17097571.

7. Hinckley MD, Milki AA. 1000 office-based hysteroscopies prior to in vitro fertilization: feasibility and findings. JSLS. 2004; 8(2): 103-107, indexed in Pubmed: 15119651.

8. Jachymski T, Moczulska H, Guzowski G, et al. Conservative treatment of abnormally located intrauterine pregnancies (cervical and cesarean scar pregnancies): a multicenter analysis (Polish series). J Matern Fetal Neonatal Med. 2018 [Epub ahead of print]: 1-6, doi: 10.1080/14767058.2018.1514009, indexed in Pubmed: 30122076.

9. Maheux-Lacroix S, Li F, Bujold E, et al. Cesarean Scar Pregnancies: A Systematic Review of Treatment Options. J Minim Invasive Gynecol. 2017; 24(6): 915-925, doi: 10.1016/j.jmig.2017.05.019, indexed in Pubmed: 28599886.

10. Smit JG, Kasius JC, Eijkemans MJC, et al. Hysteroscopy before in-vitro fertilisation (inSIGHT): a multicentre, randomised controlled trial. Lancet. 2016; 387(10038): 2622-2629, doi: 10.1016/S0140-6736(16)00231-2, indexed in Pubmed: 27132052.

11. El-Toukhy $T$, Campo R, Khalaf $\mathrm{Y}$, et al. Hysteroscopy in recurrent in-vitro fertilisation failure (TROPHY): a multicentre, randomised controlled trial. Lancet. 2016; 387(10038): 2614-2621, doi: 10.1016/S01406736(16)00258-0, indexed in Pubmed: 27132053.

12. Armstrong SC, Showell M, Stewart EA, et al. Baseline anatomical assessment of the uterus and ovaries in infertile women: a systematic review of the evidence on which assessment methods are the safest and most effective in terms of improving fertility outcomes. Hum Reprod Update. 2017; 23(5): 533-547, doi: 10.1093/humupd/dmx019, indexed in Pubmed: 28903473.

13. Di Spiezio Sardo A, Di Carlo C, Minozzi S, et al. Efficacy of hysteroscopy in improving reproductive outcomes of infertile couples: a systematic review and meta-analysis. Hum Reprod Update. 2016; 22(4): 479-496, doi: 10.1093/humupd/dmw008, indexed in Pubmed: 27008893.

14. Price TM, Harris JB. Fulminant hepatic failure due to herpes simplex after hysteroscopy. Obstet Gynecol. 2001; 98(5 Pt 2): 954-956, indexed in Pubmed: 11704219.

15. Shalev J, Levi T, Orvieto R, et al. Emergency hysteroscopic treatment of acute severe uterine bleeding. J Obstet Gynaecol. 2004; 24(2): 152-154, doi: 10.1080/01443610410001645442, indexed in Pubmed: 14766451.

16. Nappi L, Sorrentino F, Angioni S, et al. The use of laser in hysteroscopic surgery. Minerva Ginecol. 2016; 68(6): 722-726, indexed in Pubmed: 26954490.

17. Unfried G, Wieser F, Albrecht A, et al. Flexible versus rigid endoscopes for outpatient hysteroscopy: a prospective randomized clinical trial. Hum Reprod. 2001; 16(1): 168-171, doi: 10.1093/humrep/16.1.168, indexed in Pubmed: 11139557.

18. Umranikar S, Clark TJ, Saridogan E, et al. British Society for Gynaecological Endoscopy /European Society for Gynaecological Endoscopy Guideline Development Group for Management of Fluid Distension Media in Operative Hysteroscopy. BSGE/ESGE guideline on management of fluid distension media in operative hysteroscopy. Gynecol Surg. 2016; 13(4): 289-303, doi: 10.1007/s10397-016-0983-z, indexed in Pubmed: 28003797

19. AAGL Practice Report: Practice Guidelines for the Management of Hysteroscopic Distending Media. J Minim Invasive Gynecol. 2013; 20(2): 137-148, doi: 10.1016/j.jmig.2012.12.002. 
20. Shankar M, Davidson A, Taub N, et al. Randomised comparison of distension media for outpatient hysteroscopy. BJOG. 2004; 111(1): 57-62, indexed in Pubmed: 14687053

21. Cooper NAM, Smith P, Khan KS, et al. A systematic review of the effect of the distension medium on pain during outpatient hysteroscopy. Fertil Steril. 2011; 95(1): 264-271, doi: 10.1016/j.fertnstert.2010.04.080, indexed in Pubmed: 20576262.

22. Loffer FD. Complications of hysteroscopy-their cause, prevention, and correction. J Am Assoc Gynecol Laparosc. 1995; 3(1): 11-26, indexed in Pubmed: 9050612.

23. Ludwin A, Ludwin I, Pityński K, et al. Transrectal ultrasound-guided hysteroscopic myomectomy of submucosal myomas with a varying degree of myometrial penetration. J Minim Invasive Gynecol. 2013; 20(5): 672-685, doi: 10.1016/j.jmig.2013.05.001, indexed in Pubmed: 23850363.

24. Kresowik JD, Syrop $\mathrm{CH}$, Van Voorhis BJ, et al. Ultrasound is the optimal choice for guidance in difficult hysteroscopy. Ultrasound Obstet Gynecol. 2012; 39(6): 715-718, doi: 10.1002/uog.11072, indexed in Pubmed: 22173892

25. Coccia ME, Becattini C, Bracco GL, et al. Intraoperative ultrasound guidance for operative hysteroscopy. A prospective study. J Reprod Med. 2000; 45(5): 413-418, indexed in Pubmed: 10845176.

26. Bettocchi $S$, Bramante $S$, Bifulco $G$, et al. Challenging the cervix: strategies to overcome the anatomic impediments to hysteroscopy: analysis of 31,052 office hysteroscopies. Fertil Steril. 2016; 105(5): e16-e17, doi: 10.1016/j.fertnstert.2016.01.030, indexed in Pubmed: 26873675.

27. da Costa AR, Pinto-Neto AM, Amorim M, et al. Use of misoprostol prior to hysteroscopy in postmenopausal women: a randomized, placebo-controlled clinical trial. J Minim Invasive Gynecol. 2008; 15(1): 67-73, doi: 10.1016/j.jmig.2007.08.596, indexed in Pubmed: 18262147.

28. Singh N, Ghosh B, Naha M, et al. Vaginal misoprostol for cervical priming prior to diagnostic hysteroscopy--efficacy, safety and patient satisfaction: a randomized controlled trial. Arch Gynecol Obstet. 2009; 279(1): 37-40, doi: 10.1007/s00404-008-0666-8, indexed in Pubmed: 18449549.

29. Hwang JiY, Song SH. Optimal Dose of Vaginal Misoprostol for Cervical Ripening before Hysteroscopy: A Randomized Double-Blind Study. J Minim Invasive Gynecol. 2018; 25(6): 1031-1034, doi: 10.1016/j. jmig.2018.01.022, indexed in Pubmed: 29409965.

30. Al-Fozan H, Firwana B, Al Kadri H, et al. Preoperative ripening of the cervix before operative hysteroscopy. Cochrane Database Syst Rev. 2015(4): CD005998, doi: 10.1002/14651858.CD005998.pub2, indexed in Pubmed: 25906113.

31. Mulayim B, Celik NY, Onalan G, et al. Sublingual misoprostol for cervical ripening before diagnostic hysteroscopy in premenopausal women: a randomized, double blind, placebo-controlled trial. Fertil Steril. 2010; 93(7): 2400-2404, doi: 10.1016/j.fertnstert.2009.01.073, indexed in Pubmed: 19243750.

32. Wood MA, Kerrigan KL, Burns MK, et al. Overcoming the Challenging Cervix: Identification and Techniques to Access the Uterine Cavity. Obstet Gynecol Surv. 2018; 73(11):641-649, doi: 10.1097/OGX.0000000000000614, indexed in Pubmed: 30468239.

33. Grow DR, Iromloo K. Oral contraceptives maintain a very thin endometrium before operative hysteroscopy. Fertil Steril. 2006; 85(1): 204-207, doi: 10.1016/j.fertnstert.2005.06.044, indexed in Pubmed: 16412754.

34. Cooper NAM, Smith P, Khan KS, et al. Vaginoscopic approach to outpatient hysteroscopy: a systematic review of the effect on pain. BJOG. 2010; 117(5): 532-539, doi: 10.1111/j.1471-0528.2010.02503.x, indexed in Pubmed: 20374594.

35. Smith PP, Kolhe S, O'Connor S, et al. Vaginoscopy Against Standard Treatment: a randomised controlled trial. BJOG. 2019; 126(7): 891-899, doi: 10.1111/1471-0528.15665, indexed in Pubmed: 30801889.

36. Kremer C, Duffy S, Moroney M. Patient satisfaction with outpatient hysteroscopy versus day case hysteroscopy: randomised controlled trial. BMJ. 2000; 320(7230): 279-282, indexed in Pubmed: 10650023.

37. Salazar CA, Isaacson KB. Office Operative Hysteroscopy: An Update. J Minim Invasive Gynecol. 2018; 25(2): 199-208, doi: 10.1016/j. jmig.2017.08.009, indexed in Pubmed: 28803811.

38. Readman E, Maher PJ. Pain relief and outpatient hysteroscopy: a literature review. J Am Assoc Gynecol Laparosc. 2004; 11(3): 315-319, indexed in Pubmed: 15559340.

39. Paulo $\mathrm{AA}$, Solheiro $\mathrm{MH}$, Paulo $\mathrm{CO}$, et al. What proportion of women refers moderate to severe pain during office hysteroscopy with a mini-hysteroscope? A systematic review and meta-analysis. Arch Gynecol
Obstet. 2016; 293(1): 37-46, doi: 10.1007/s00404-015-3836-5, indexed in Pubmed: 26253336.

40. Angioli R, De Cicco Nardone C, Plotti F, et al. Use of music to reduce anxiety during office hysteroscopy: prospective randomized trial. J Minim Invasive Gynecol. 2014; 21(3):454-459, doi: 10.1016/j.jmig.2013.07.020, indexed in Pubmed: 23962572

41. De laco P, Marabini A, Stefanetti M, et al. Acceptability and pain of outpatient hysteroscopy. J Am Assoc Gynecol Laparosc. 2000; 7(1): 71-75, indexed in Pubmed: 10648742.

42. Kremer C, Barik S, Duffy S. Flexible outpatient hysteroscopy without anaesthesia: a safe, successful and well tolerated procedure. $\mathrm{Br} \mathrm{J} \mathrm{Ob-}$ stet Gynaecol. 1998; 105(6): 672-676, doi: 10.1111/j.1471-0528.1998. tb10185.x, indexed in Pubmed: 9647161.

43. Giorda G, Scarabelli C, Franceschi S, et al. Feasibility and pain control in outpatient hysteroscopy in postmenopausal women: a randomized trial. Acta Obstet Gynecol Scand. 2000; 79(7): 593-597, indexed in Pubmed: 10929961.

44. Mattar OM, Abdalla AR, Shehata MSA, et al. Efficacy and safety of tramadol in pain relief during diagnostic outpatient hysteroscopy: systematic review and meta-analysis of randomized controlled trials. Fertil Steril. 2019; 111(3): 547-552, doi: 10.1016/j.fertnstert.2018.10.026, indexed in Pubmed: 30711222

45. Tam WH, Yuen PM. Use of diclofenac as an analgesic in outpatient hysteroscopy: a randomized, double-blind, placebo-controlled study. Fertil Steril. 2001; 76(5): 1070-1072, doi: 10.1016/s0015-0282(01)02832-1, indexed in Pubmed: 11704141.

46. Cooper NAM, Khan KS, Clark TJ. Local anaesthesia for pain control during outpatient hysteroscopy: systematic review and meta-analysis. BMJ. 2010; 340: c1130, doi: 10.1136/bmj.c1130, indexed in Pubmed: 20332307.

47. Tangsiriwatthana T, Sangkomkamhang US, Lumbiganon P, et al. Paracervical local anaesthesia for cervical dilatation and uterine intervention. Cochrane Database Syst Rev. 2013(9): CD005056, doi: 10.1002/14651858. CD005056.pub3, indexed in Pubmed: 24085642

48. American College of Obstetricians and Gynecologists. Quality and safety in women's health care. 2nd ed. American College of Obstetricians and Gynecologists, Washington, DC 2010.

49. Narice BF, Delaney B, Dickson JM. Endometrial sampling in low-risk patients with abnormal uterine bleeding: a systematic review and meta-synthesis. BMC Fam Pract. 2018; 19(1): 135, doi: 10.1186/s12875018-0817-3, indexed in Pubmed: 30060741.

50. Epstein E, Ramirez A, Skoog L, et al. Dilatation and curettage fails to detect most focal lesions in the uterine cavity in women with postmenopausal bleeding. Acta Obstet Gynecol Scand. 2001; 80(12): 1131-1136, indexed in Pubmed: 11846711.

51. Trimble CL, Method M, Leitao M, et al. Society of Gynecologic Oncology Clinical Practice Committee. Management of endometrial precancers. Obstet Gynecol. 2012; 120(5): 1160-1175, doi: http://10.1097/AOG.0b013e31826bb121, indexed in Pubmed: 23090535.

52. The American College of Obstetricians and Gynecologists and Society of Gynecologic Oncology. Practice Bulletin No. 149: Endometrial cancer. Obstet Gynecol. 2015; 125(4): 1006-1026, doi: 10.1097/01. AOG.0000462977.61229.de, indexed in Pubmed: 25798986.

53. The American College of Obstetricians and Gynecologists' Committee on Gynecologic Practice. OPINION Number 734. The Role of Transvaginal Ultrasonography in Evaluating the Endometrium of Women With Postmenopausal Bleeding. Obstetrics \& Gynecology. 2018; 131(5): e124-e129.

54. Dijkhuizen FP, Mol BW, Brölmann HA, et al. The accuracy of endometrial sampling in the diagnosis of patients with endometrial carcinoma and hyperplasia: a meta-analysis. Cancer. 2000; 89(8): 1765-1772, indexed in Pubmed: 11042572

55. Bakour S, Timmermans A, Mol B, et al. Management of women with postmenopausal bleeding: evidence-based review. The Obstetrician \& Gynaecologist. 2012; 14(4):243-249, doi: 10.1111/j.1744-4667.2012.00129.x.

56. Chang YN, Zhang Y, Wang YJ, et al. Effect of hysteroscopy on the peritoneal dissemination of endometrial cancer cells: a meta-analysis. Fertil Steril. 2011; 96(4): 957-961, doi: 10.1016/j.fertnstert.2011.07.1146, indexed in Pubmed: 21872230.

57. Polyzos NP, Mauri D, Tsioras S, et al. Intraperitoneal dissemination of endometrial cancer cells after hysteroscopy: a systematic review and meta-analysis. Int J Gynecol Cancer. 2010; 20(2): 261-267, indexed in Pubmed: 20169669.

58. Obermair A, Geramou M, Gucer F, et al. Does hysteroscopy facilitate tumor cell dissemination? Incidence of peritoneal cytology from patients with early stage endometrial carcinoma following dilatation and 
curettage (D \& C) versus hysteroscopy and D \& C. Cancer. 2000; 88(1): 139-143, indexed in Pubmed: 10618616.

59. Arikan $\mathrm{G}$, Reich $\mathrm{O}$, Weiss U, et al. Are endometrial carcinoma cells disseminated at hysteroscopy functionally viable? Gynecol Oncol. 2001; 83(2): 221-226, doi: 10.1006/gyno.2001.6380, indexed in Pubmed: 11606075.

60. Ben-Arie A, Tamir S, Dubnik S, et al. Does hysteroscopy affect prognosis in apparent early-stage endometrial cancer? Int J Gynecol Cancer. 2008; 18(4): 813-819, doi: 10.1111/j.1525-1438.2007.01076.x, indexed in Pubmed: 17961159.

61. Selvaggi L, Cormio G, Ceci O, et al. Hysteroscopy does not increase the risk of microscopic extrauterine spread in endometrial carcinoma. Int J Gynecol Cancer. 2003; 13(2): 223-227, indexed in Pubmed: 12657128.

62. Jansen FW, Vredevoogd CB, van Ulzen $\mathrm{K}$, et al. Complications of hysteroscopy: a prospective, multicenter study. Obstet Gynecol. 2000; 96(2): 266-270, indexed in Pubmed: 10908775.

63. Aas-Eng MK, Langebrekke A, Hudelist G. Complications in operative hysteroscopy - is prevention possible? Acta Obstet Gynecol Scand. 2017; 96(12): 1399-1403, doi: 10.1111/aogs.13209, indexed in Pubmed: 28832907.

64. Vilos GA, Brown S, Graham G, et al. Genital tract electrical burns during hysteroscopic endometrial ablation: report of 13 cases in the United States and Canada. J Am Assoc Gynecol Laparosc. 2000; 7(1): 141-147, indexed in Pubmed: 10648756.

65. Sentilhes $\mathrm{L}$, Sergent $\mathrm{F}$, Roman $\mathrm{H}$, et al. Late complications of operative hysteroscopy: predicting patients at risk of uterine rupture during subsequent pregnancy. Eur J Obstet Gynecol Reprod Biol. 2005; 120(2): $134-$ 138, doi: 10.1016/j.ejogrb.2004.10.010, indexed in Pubmed: 15925040.

66. Brooks PG. Venous air embolism during operative hysteroscopy. J Am Assoc Gynecol Laparosc. 1997; 4(3): 399-402, indexed in Pubmed: 9154793.

67. Sethi N, Chaturvedi R, Kumar K. Operative hysteroscopy intravascular absorption syndrome: A bolt from the blue. Indian J Anaesth. 2012; 56(2): 179-182, doi: 10.4103/0019-5049.96342, indexed in Pubmed: 22701213.

68. Aydeniz B, Gruber IV, Schauf B, et al. A multicenter survey of complications associated with 21,676 operative hysteroscopies. Eur J Obstet Gynecol Reprod Biol. 2002; 104(2): 160-164, indexed in Pubmed: 12206931.

69. Shveiky D, Rojansky N, Revel A, et al. Complications of hysteroscopic surgery: „Beyond the learning curve”. J Minim Invasive Gynecol. 2007; 14(2): 218-222, doi: 10.1016/j.jmig.2006.07.019, indexed in Pubmed: 17368260 .
70. GARRY R, HASHAM F, KOKRI M, et al. The Effect of Pressure on Fluid Absorption During Endometrial Ablation. J Gynecol Surg. 1992; 8(1): 1-10, doi: 10.1089/gyn.1992.8.1.

71. Paschopoulos M, Polyzos NP, Lavasidis LG, et al. Safety issues of hysteroscopic surgery. Ann NY Acad Sci. 2006; 1092: 229-234, doi: 10.1196/annals.1365.019, indexed in Pubmed: 17308147.

72. Munro MG, Critchley HOD, Broder MS, et al. FIGO Working Group on Menstrual Disorders. FIGO classification system (PALM-COEIN) for causes of abnormal uterine bleeding in nongravid women of reproductive age. Int J Gynaecol Obstet. 2011; 113(1): 3-13, doi: 10.1016/j.ijgo.2010.11.011, indexed in Pubmed: 21345435.

73. BAGGISH M, BRILL A, ROSENSWEIG B, et al. Fatal Acute Glycine and Sorbitol Toxicity During Operative Hysteroscopy. Journal of Gynecologic Surgery. 1993; 9(3): 137-143, doi: 10.1089/gyn.1993.9.137.

74. AAGL Elevating Gynecologic Surgery, AAGL Elevating Gynecologic Surgery. AAGL Practice Report: Practice Guidelines on Intrauterine Adhesions Developed in Collaboration With the European Society of Gynaecological Endoscopy (ESGE). J Minim Invasive Gynecol. 2017; 24(5): 695-705, doi: 10.1016/j.jmig.2016.11.008, indexed in Pubmed: 28473177.

75. Healy MWu, Schexnayder B, Connell MT, et al. Intrauterine adhesion prevention after hysteroscopy: a systematic review and meta-analysis. Am J Obstet Gynecol. 2016; 215(3): 267-275.e7, doi: 10.1016/j. ajog.2016.05.001, indexed in Pubmed: 27173082

76. Di Spiezio Sardo A, Calagna G, Scognamiglio M, et al. Prevention of intrauterine post-surgical adhesions in hysteroscopy. A systematic review. Eur J Obstet Gynecol Reprod Biol. 2016; 203: 182-192, doi: 10.1016/j. ejogrb.2016.05.050, indexed in Pubmed: 27337414.

77. ACOG Practice Bulletin No. 195 Summary: Prevention of Infection After Gynecologic Procedures. Obstet Gynecol. 2018; 131(6): 1177-1179, doi: 10.1097/AOG.0000000000002672, indexed in Pubmed: 29794671.

78. ACOG Committee on Practice Bulletins--Gynecology. ACOG practice bulletin No. 104: antibiotic prophylaxis for gynecologic procedures. Obstet Gynecol.2009;113(5):1180-1189, doi:10.1097/AOG.0b013e3181a6d011, indexed in Pubmed: 19384149.

79. Florio P, Nappi L, Mannini L, et al. Prevalence of Infections After In-Office Hysteroscopy in Premenopausal and Postmenopausal Women. J Minim Invasive Gynecol. 2019; 26(4): 733-739, doi: 10.1016/j.jmig.2018.06.021, indexed in Pubmed: 30138739. 